\title{
Terson's syndrome: neurosurgical considerations on the subject of a rare case with ophthalmological sequelae
}

\author{
Bruno Lourenço Costa ${ }^{1}$, Filipe Mira Ferreira ${ }^{2}$, \\ Augusto Barbosa ${ }^{3}$, José Lozano Lopes ${ }^{4}$, Armando Lopes ${ }^{5}$ \\ Centro Hospitalar e Universitário de Coimbra, Coimbra, Portugal.
}

\begin{abstract}
According to prospective studies, vitreous hemorrhage may be diagnosed in $8 \%-27 \%$ of the patients with aneurysmal subarachnoid hemorrhage (SAH) (Terson's syndrome) and has been associated with a bad neurological outcome. In spite of its incidence and prognostic value, vitreous hemorrhage is underdiagnosed. We describe the case of a 48 year-old woman who was diagnosed with a SAH due to the rupture of an aneurysm of the right middle cerebral artery bifurcation that was surgically treated with minimal neurological morbidity. However, due to vitreous hemorrhage in the right eye, the patient developed visual loss that did not recovered after proper surgical treatment. In the context of the present case we take a timely review of the literature, discussing the incidence, pathophysiology, treatment and prognosis of Terson's syndrome. The reported case stresses that the natural history of Terson's syndrome is not always synonymous with good outcome. Significant visual sequelae due to vitreous hemorrhage are very rare after proper conservative or surgical treatment. The severe visual loss of this patient emphasizes the need for a systematic, early and serial ophthalmological evaluation of all patients with aneurysmal SAH.
\end{abstract}

\section{KEYWORDS}

Intracranial aneurysm, vitreous hemorrhage, subarachnoid hemorrhage.

\section{RESUMO}

Síndrome de Terson: considerações neurocirúrgicas a propósito de um raro caso com sequelas oftalmológicas

De acordo com estudos prospectivos, a hemorragia do vítreo pode ser diagnosticada em $8 \%-27 \%$ dos doentes com hemorragia subaracnóidea aneurismática (síndrome de Terson) e foi associada a mau prognóstico neurológico. Apesar da sua incidência e valor prognóstico, a hemorragia do vítreo é subdiagnosticada. Os autores descrevem o caso de uma doente de 48 anos, diagnosticada com hemorragia subaracnóidea por rotura de um aneurisma da bifurcação da artéria cerebral média direita, que foi tratado cirurgicamente com mínima morbilidade neurológica. Contudo, por causa da hemorragia do vítreo do olho direito, a doente desenvolveu perda de visão, que não recuperou após tratamento adequado. No contexto do presente caso, revimos a literatura e discutimos a incidência, a fisiopatologia, o diagnóstico e o prognóstico da síndrome de Terson. O caso descrito enfatiza que a história natural da síndrome de Terson não é necessariamente sinônimo de boa evolução. Sequelas visuais significativas após hemorragia do vítreo são muito raras após tratamento conservador ou cirúrgico. A importante perda de visão dessa doente enfatiza a necessidade de avaliação oftalmológica sistemática, precoce e seriada de todos os doentes com hemorragia subaracnóidea aneurismática.

\section{PALAVRAS-CHAVE}

Aneurisma intracraniano, hemorragia do vítreo, hemorragia subaracnóidea.

1 Resident of Neurosurgery, Department of Neurosurgery, Centro Hospitalar e Universitário de Coimbra, Coimbra, Portugal.

2 Resident of Ophthalmology, Department of Ophthalmology, Centro Hospitalar e Universitário de Coimbra, Coimbra, Portugal.

3 Ophtalmologist, Department of Ophthalmology, Centro Hospitalar e Universitário de Coimbra, Coimbra, Portugal.

4 Neurosurgeon, head of Department, Department of Neurosurgery, Centro Hospitalar e Universitário de Coimbra, Coimbra, Portugal.

5 Neurosurgeon, Department of Neurosurgery, Centro Hospitalar e Universitário de Coimbra, Coimbra, Portugal. 


\section{Introduction}

The ophthalmologists Moritz Litten and Albert Terson were the first to report on the association between aneurysmal subarachnoid hemorrhage (SAH) and vitreous hemorrhage (Terson's syndrome). Later papers related spontaneous SAH to other forms of intraocular hemorrhage (sub-retinal, intra-retinal, pre-retinal and sub-hyaloid). More recently, intraocular hemorrhages were associated with other neuropathologies: traumatic brain injury, spontaneous or post-surgical intracranial or spinal hemorrhages, occipito-cervical decompressions, neuroendoscopic procedures, epidural injections, carotid occlusions and angiographies.

Although intraocular hemorrhages are frequent among patients with aneurysmal subarachnoid hemorrhage and should be associated with potential complications, they are often neglected in the neurosurgical literature and underdiagnosed in clinical practice. ${ }^{1,2} \mathrm{We}$ describe here the case of a patient with an aneurysmal $\mathrm{SAH}$ in whom vitreous hemorrhage caused severe visual loss.

\section{Case report}

A 48 year-old woman, with chronic depression and irrelevant neurologic or ophthalmologic history, was admitted to the emergency department due to two generalized tonic-clonic seizures. The patient presented with meningeal signs, Glasgow Coma Scale score 12 (E3M6V3), marked prostration and no gross motor deficits (Hunt and Hess grade 3, WFNS grade 4). Brain $\mathrm{CT}$ showed an extensive $\mathrm{SAH}$, diffuse cerebral edema and incipient hydrocephalus (Figure 1A). CT angiography revealed a sacular aneurysm of the right MCA bifurcation (Figure 1B).

Six days after the SAH, the patient was more alert and complained of visual loss. Ophthalmologic examination revealed that visual acuity was 10/10 in the left eye and reduced to light perception in the right eye. Biomicroscopy and tonometry were normal bilaterally. Fundus photography showed vitreous hemorrhage in the right eye, but it was found to be normal in the left eye (Figure 2). Ultrasound demonstrated medium amplitude echoes in the intermediate vitreous and flat retina in the right eye.

Clipping of the aneurysm, after temporary clipping of the right internal carotid artery for 10 minutes, using a right pterional and transylvian approach was performed. The patient was discharged ten days after the surgery, showing a Glasgow Coma Scale score of 15, marked loss of visual acuity in the right eye and mild left central facial paresis related to a little nuclear and capsular area of infarction.

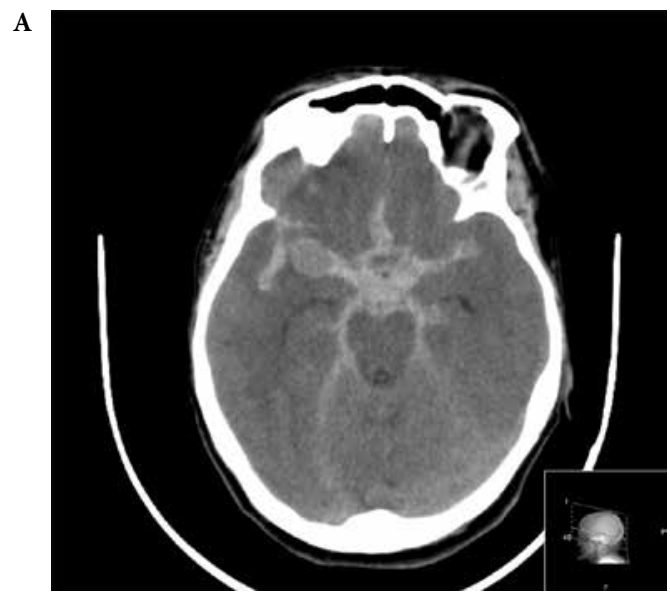

B

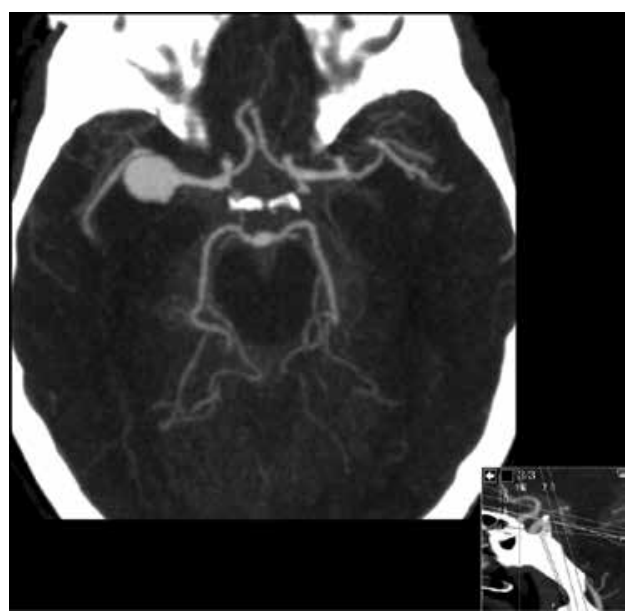

Figure 1 - Brain CT performed at admission (A), showing a SAH extending to the basal cisterns and sylvian fissures, an image in the right sylvian fissure corresponding to a saccular aneurysm, as well as diffuse cerebral edema and incipient hydrocephalus. CT angiography showing a saccular aneurysm of the right middle cerebral artery bifurcation (B).

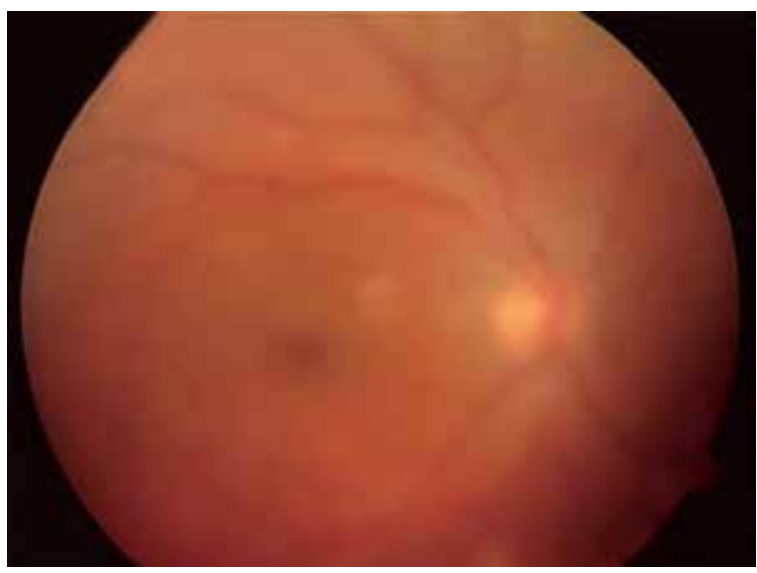

Figure 2 - Fundus photography of the right eye performed six days after the SAH showing vitreous and probable intra-retinal hemorrhages located in the posterior pole. 
After non-surgical treatment, one month after the $\mathrm{SAH}$, phacoemulsification of cortical and nuclear cataracts intra-operatively observed, posterior mechanical vitrectomy via pars plana $23 \mathrm{G}$ and posterior chamber lens $(+21 \mathrm{D})$ implantation were performed in the right eye. Five months after the ophthalmological surgery, the corrected visual acuity in the right eye was $2 / 10$ and fundoscopy revealed a clear vitreous as well as vascular retinal tortuosity, foveal pigmentary changes and epiretinal membranes (Figure 3). Some visual improvement would be expected after surgical removal of epiretinal membranes but the patient refused the treatment.

Three years after clipping the aneurysm, the patient showed a mild left central facial paresis. In regard to ophthalmologic outcome, her visual acuity was $2 / 10$ in the right eye and $9 / 10$ in the left eye. She performed her normal daily activities, resumed her job with limitations and was unable to drive.

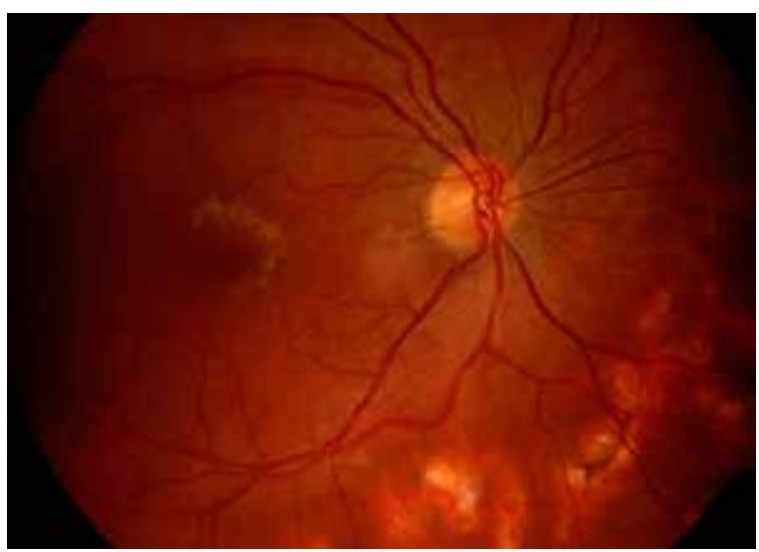

Figure 3 - Fundus photography of the right eye performed five months after right vitrectomy showing a clear vitreous as well as vascular retinal tortuosity, foveal pigmentary changes and epiretinal membranes. Those secondary lesions could explain the unsatisfactory visual improvement after vitrectomy.

\section{Discussion}

Aneurysmal SAH has an incidence of 6-8/100,000/ year in most Western countries. ${ }^{3,4}$ Intraocular hemorrhages, in general, may be diagnosed in 10\%-50\% and vitreous hemorrhage, according to prospective studies, in $8 \%-27 \%$ of patients with spontaneous SAH. ${ }^{5-12}$ The true incidence is probably higher because some patients die before the first ophthalmological evaluation. Retrospective studies point to an incidence of $2 \%-5 \%$ because patients with aneurysmal SAH are subject to an ophthalmological examination on a non-regular basis., ${ }^{5,12-14}$ The incidence of Terson's syndrome is not gender or age related and, in almost half of the cases, the vitreous hemorrhage is bilateral..$^{5-8,10,15} \mathrm{~A}$ relation between localization and size of the aneurysm and the incidence and laterality of intraocular hemorrhage has not been established. ${ }^{1,6,10}$ In a few cases, visual complaints are the main or even the sole manifestation of the aneurysmal rupture. 8,16

Vitreous hemorrhage in patients with aneurysmal $\mathrm{SAH}$ has been related to worse neurological status at admission (Glasgow Coma Scale, Hunt and Hess grade and WFNS grade), higher initial and maximal intracranial pressures, higher re-hemorrhage rates and higher neurological morbidity and mortality. $1,6-8,10,12,13,17$ The prognostic significance of other types of intraocular hemorrhage has not been studied in detail. ${ }^{13,18}$

More than a century after the initial report of Terson's syndrome, controversy about its pathophysiology still remains. A sudden and massive rise in intracranial pressure seems to be the focal point. According to initial explanations, intracranial hypertension would force the direct passage of blood from the subarachnoid space to the pre-retinal space through the lamina cribosa. ${ }^{19-21}$ Others consider that the intracranial hypertension transmitted to the optic nerve sheath would cause acute compression and obstruction of the central vein of the retina and retino-choroidal anastomoses with subsequent vascular disruption and hemorrhage in the posterior segment of the eye. ${ }^{8,10,13,15,22}$

In almost every case, intraocular hemorrhages develop during the first 24 hours after intracranial hemorrhage. ${ }^{6,23,24}$ They are diagnosed by fundoscopy, ocular fundus photography and ocular ultrasound. However, we stress that a fundus examination in mydriasis should be undertaken only after the acute phase of the intracranial hemorrhage. Standard brain CT has little accuracy with regard to intraocular hemorrhages. ${ }^{25}$

In most cases, vitreous hemorrhage is absorbed spontaneously in a few months. A regular ophthalmological examination is recommended because some patients present slow hemorrhage absorption or develop complications related to persistence of blood in the vitreous: hemosiderosis, cataract, macular abnormalities, retinal detachment, proliferative retinopathy and intraocular hypertension. ${ }^{26}$ Vitrectomy via pars plana is very effective in clearing the vitreous hemorrhage and allows prevention of those complications. Several clinical studies report excellent functional results and very low morbidity after vitrectomy via pars plana. ${ }^{6,24,27,28}$ In a group of 23 adults with Terson's syndrome, Kuhn et al..$^{27}$ reported a rapid and substantial visual improvement in $25 / 26$ eyes (96\%) with 21 eyes (81\%) achieving $\geq 20 / 30$ final visual acuity. The same authors reviewed the literature and concluded that only in 4/157 eyes (2.5\%), the visual recovery was unexpectedly unsatisfactory.

In this case, a patient with an aneurysmal SAH presented with poor neurological status at admission. However, after surgical treatment, the neurological morbidity was minimal. The diagnosis of visual loss was established early but only after the patient's complaints. 
However, we must emphasize that some patients, due to their neurological status, are not able to make clear and timely complaints. An early vitrectomy allowed some visual improvement but secondary lesions already developed such as foveal pigmentary changes and epiretinal membranes impaired significantly the ophthalmological outcome. The reported case stresses that Terson's syndrome may seldom cause dramatic ophthalmological sequelae. In very rare rare instances, even an early diagnosis and a proper treatment cannot prevent the visual impairment.

In conclusion, the risk of irreversible visual sequelae related to vitreous hemorrhage makes an ophthalmological examination on a systematic, early and serial basis mandatory for all patients with aneurysmal SAH and, probably, for all patients with severe intracranial hypertension. The outcome observed prompted a change in the guidelines for the follow-up of patients with aneurysmal SAH in our institution.

\section{Disclosure}

No conflict of interest to declare.

\section{References}

1. McCarron MO, Alberts MJ, McCarron P. A systematic review of Terson's syndrome: frequency and prognosis after subarachnoid haemorrhage. J Neurol Neurosurg Psychiatry. 2004;75(3):491-3.

2. Wiethölter S, Steube D, Stotz HP. [Terson syndrome: a frequently missed ophthalmologic complication in subarachnoid hemorrhage]. Zentralbl Neurochir. 1998;59(3):166-70.

3. Broderick JP, Brott T, Tomsick T, Miller R, Huster G. Intracerebral hemorrhage more than twice as common as subarachnoid hemorrhage. J Neurosurg. 1993;78(2):188-91.

4. Linn FH, Rinkel GJ, Algra A, van Gijn J. Incidence of subarachnoid hemorrhage: role of region, year, and rate of computed tomography: a meta-analysis. Stroke. 1996;27(4):625-9.

5. Fahmy JA. Fundal haemorrhages in ruptured intracranial aneurysms. I. Material, frequency and morphology. Acta Ophthalmol (Copenh). 1973;51(3):289-98.

6. Fountas KN, Kapsalaki EZ, Lee GP, Machinis TG, Grigorian AA, Robinson JS, et al. Terson hemorrhage in patients suffering aneurismal subarachnoid hemorrhage: predisposing factors and prognostic significance. $J$ Neurosurg. 2008;109(3):439-44.

7. Frizzell RT, Kuhn F, Morris R, Quinn C, Fisher WS 3rd. Screening for ocular hemorrhages in patients with ruptured cerebral aneurysms: a prospective study of 99 patients. Neurosurgery. 1997;41(3):529-33.

8. Garfinkle AM, Danys IR, Nicolle DA, Colohan AR, Brem S. Terson's syndrome: a reversible cause of blindness following subarachnoid hemorrhage. J Neurosurg. 1992;76(5):766-71.

9. Oyakawa RT, Michels RG, Blase WP. Vitrectomy for nondiabetic vitreous hemorrhage. Am J Ophthalmol. 1983;96(4):517-25.
10. Pfausler B, Belcl R, Metzler R, Mohsenipour I, Schmutzhard E. Terson's syndrome in spontaneous subarachnoid hemorrhage: a prospective study in 60 consecutive patients. J Neurosurg. 1996;85(3):392-4.

11. Roux FX, Panthier JN, Tanghe YM, Gallina P, Oswald AM, Mérienne $L$, et al. [Terson's syndrome and intraocular complications in meningeal hemorrhages (26 cases)]. Neurochirurgie. 1991;37(2):106-10.

12. Shinoda J, Iwamura M, Iwai T, Iwata T, Hattori T, Kondo $\mathrm{H}$, et al. [Intraocular hemorrhage in ruptured intracranial aneurysm. Clinical study of 172 cases and reference to Terson's syndrome]. Neurol Med Chir (Tokyo). 1983;23(5):349-54.

13. Shaw HE Jr, Landers MB, Sydnor CF. The significance of intraocular hemorrhages due to subarachnoid hemorrhage. Ann Ophthalmol. 1977;9(11):1403-5.

14. Timberlake $\mathrm{WH}$, Kubik CS. Follow-up report with clinical and anatomical notes on 280 patients with subarachnoid hemorrhage. Trans Am Neurol Assoc. 1952;56(77th Meeting):26-30.

15. Castren JA. Pathogeneses and treatment of Tersonsyndrome. Acta Ophthalmol (Copenh). 1963;41:430-4.

16. Inoue T, Tsutsumi K, Shigeeda T. Terson's syndrome as the initial symptom of subarachnoid hemorrhage caused by ruptured vertebral artery aneurysm. Case report. Neurol Med Chir (Tokyo). 2006;46(7):344-7.

17. Medele RJ, Stummer W, Mueller AJ, Steiger HJ, Reulen HJ. Terson's syndrome in subarachnoid hemorrhage and severe brain injury accompanied by acutely raised intracranial pressure. J Neurosurg. 1998;88(5):851-4.

18. Fahmy JA. Fundal haemorrhages in ruptured intracranial aneurysms. II. Correlation with the clinical course. Acta Ophthalmol (Copenh). 1973;51(3):299-304.

19. Doubler FH, Marlow SB. A case of hemorrhage into the optic nerve sheath as a direct extension from a diffuse intrameningeal hemorrhage caused by rupture of an aneurysm of a cerebral artery. Arch Ophthalmol 1917;46:533-6.

20. Muller PJ, Deck JH. Intraocular and optic nerve sheath hemorrhage in cases of sudden intracranial hypertension. J Neurosurg. 1974;41(2):160-6.

21. Walsh FB, Hedges TR Jr. Optic nerve sheath hemorrhage. Am J Ophthalmol. 1951;34(4):509-27.

22. Toosi SH, Malton M. Terson's syndrome: significance of ocular findings. Ann Ophthalmol. 1987;19(1):7-12.

23. Manschot WA. Subarachnoid hemorrhage; intraocular symptoms and their pathogenesis. Am J Ophthalmol. 1954;38(4):501-5.

24. Vanderlinden RG, Chisholm LD. Vitreous hemorrhages and sudden increased intracranial pressure. $J$ Neurosurg. 1974;41(2):167-76.

25. Swallow CE, Tsuruda JS, Digre KB, Glaser MJ, Davidson $\mathrm{HC}$, Harnsberger HR. Terson syndrome: CT evaluation in 12 patients. AJNR Am J Neuroradiol. 1998;19(4):743-7.

26. Augsten R, Königsdörffer E, Strobel J. Surgical approach in Terson syndrome: vitreous and retinal findings. Eur $\mathrm{J}$ Ophthalmol. 2000;10(4):293-6.

27. Kuhn F, Morris R, Witherspoon CD, Mester V. Terson syndrome. Results of vitrectomy and the significance of vitreous hemorrhage in patients with subarachnoid hemorrhage. Ophthalmology. 1998;105(3):472-7.

28. Schultz PN, Sobol WM, Weingeist TA. Long-term visual outcome in Terson syndrome. Ophthalmology. 1991;98(12):1814-9.

\section{Correspondence address}

Bruno Lourenço Costa

Department of Neurosurgery, Centro Hospitalar e Universitário de Coimbra Quinta dos Vales, 3041-801 S. Martinho do Bispo, Coimbra, Portugal.

Tel.: +351 239800100; Fax: +351 239442820

E-mail: brunolourencocosta@gmail.com 